\title{
Test Dissolution of Hanford Scrap Oxide, HRA-40
}

by

H. P. Holcomb

E. l. du Pont de Nemours and Company

Savannah River Site

Aiken, South Carolina 29808

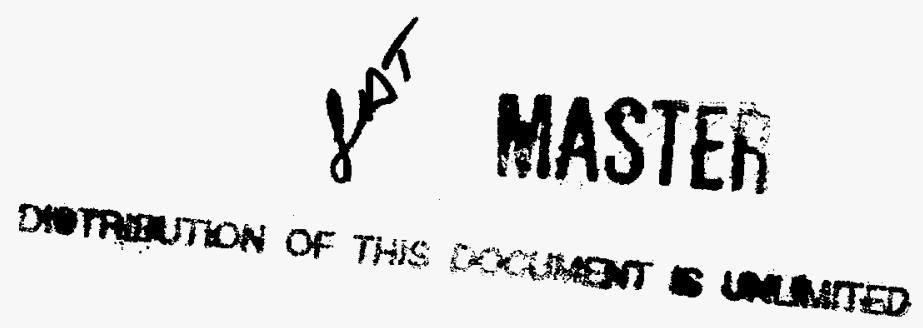

DOE Contract No.

This paper was prepared in connection with work done under the above contract number with the U. S. Department of Energy. By acceptance of this paper, the publisher and/or recipient acknowledges the U.S. Government's right to retain a nonexclusive, royalty-free license in and to any copyright covering this paper, along with the right to reproduce and to authorize others to reproduce all or part of the copyrighted paper. 


\section{DISCLAIMER}

This report was prepared as an account of work sponsored by an agency of the United States Government. Neither the United States Government nor any agency thereof, nor any of their employees, makes any warranty, express or implied, or assumes any legal liability or responsibility for the accuracy, completeness, or usefulness of any information, apparatus, product, or process disclosed, or represents that its use would not infringe privately owned rights. Reference herein to any specific commercial product, process, or service by trade name, trademark, manufacturer, or otherwise does not necessarily constitute or imply its endorsement, recommendation, or favoring by the United States Government or any agency thereof. The views and opinions of authors expressed herein do not necessarily state or reflect those of the United States Government or any agency thereof.

This report has been reproduced directly from the best available copy.

Available to DOE and DOE contractors from the Office of Scientific and Technical Information, P. O. Box 62, Oak Ridge, TN 37831; prices available from (423) 576-8401.

Available to the public from the National Technical Information Service, U. S. Department of Commerce, 5285 Port Royal Road, Springfield, VA 22161. 


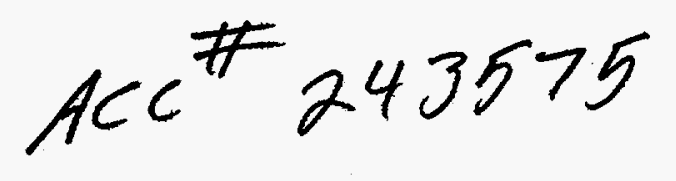

DPSPU $-88-272-23$

\section{INFORMATION ONLY}

TEST DISSOLUTION OF HANFORD SCRAP OXIDE, HRA-40

\section{DISTRIBUTION}

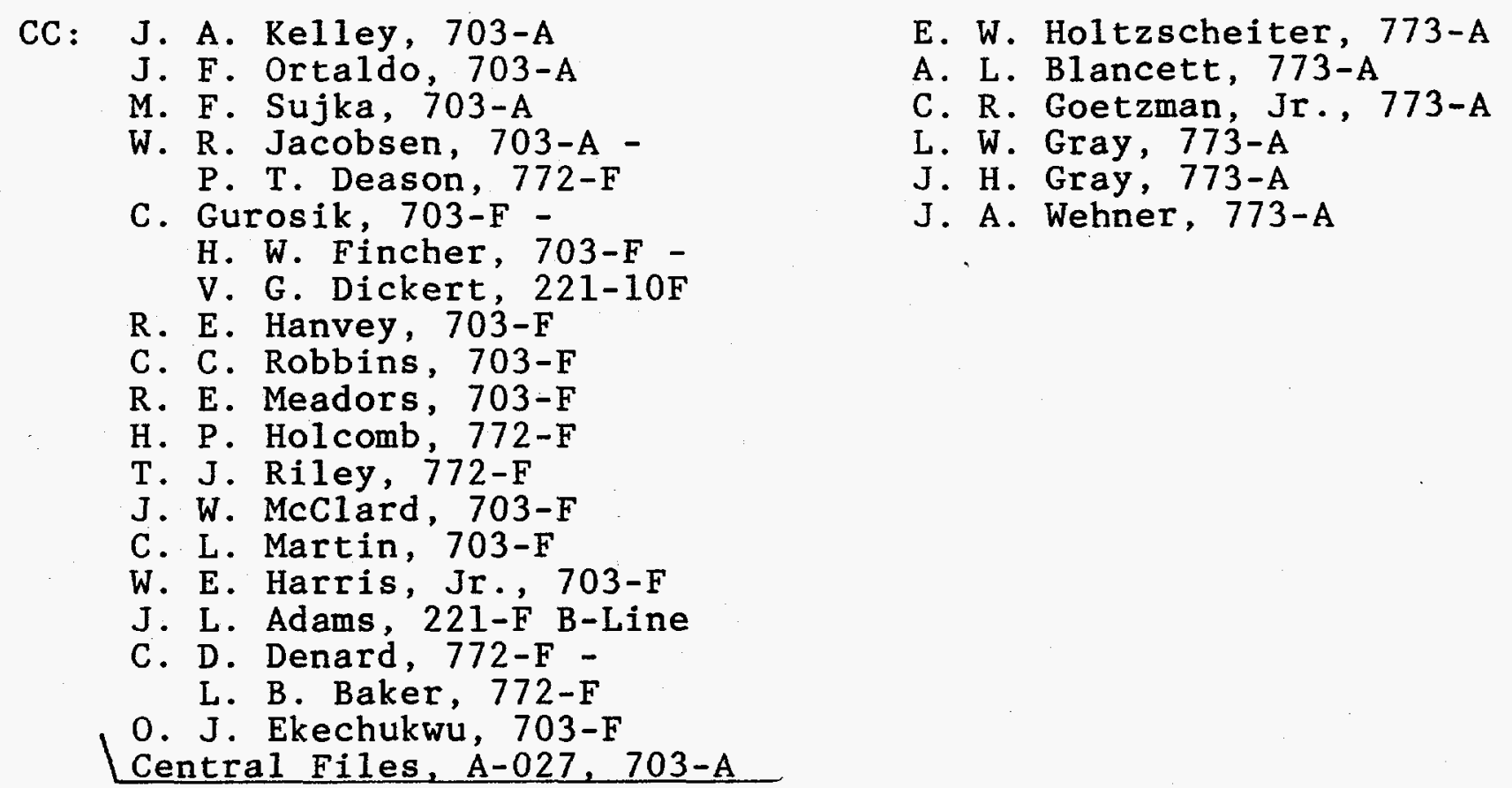




\section{DISCLAIMER}

Portions of this document may be illegible in electronic image products. Images are produced from the best available original document. 
INTER-OFFICE MEMORANDUM

Savannah River Plant

DPSPU $-88-272-23$

February 16,1988
Hanford

Plutonium

Oxide

Dissolution

Analys is

TO: J. L. ADAMS, 221-F, B-LINE

FROM: H. P. HOLCOMB, 772-F HP

TEST DISSOLUTION OF HANFORD SCRAP OXIDE, HRA-40

INTRODUCTION AND SUMMARY

Two portions from a single sample of Hanford scrap plutonium oxide $\left(12 \% \mathrm{Pu}^{240}\right)$, account HRA-40, were dissolved in the Separations Technology Laboratory as you requested. Test conditions, including oxide-to-dissolvent ratio were very similar to those used in the process. Both test portions dissolved quite readily in $14 \mathrm{M} \mathrm{HNO}_{3}$ - $0.2 \mathrm{M} \mathrm{HF}$ in a boiling water bath. Efficient agitation of the oxide in the dissolvent was instrumental in ensuring quick, thorough dissolution.

Small residues of siliceous materials appeared in both tests. These residues were produced from a combination of the silica dissolved from the test container, a Kimax ${ }^{\circledR}$ graduated centrifuge cone, plus the silica impurity in the oxide itself. The former was the primary source of the silica in the first of our tests. Siliceous solids can build up in the process dissolver as a result of continued dissolution of Hanford material containing silica as an impurity. A previous studyl, following the dissolution of HRA-37 in 1986, showed silicon to be the primary constituent of actual process residues analyzed by SEM/XRF.

Laboratories Department emission spectrographic analysis found $65 \mathrm{ppm}$ silicon in the HRA-40 sample provided me. Hanford reported an average silicon content of $12 \mathrm{ppm}$ in the six batches of HRA-40 sent to SRP.

Plutonium accountability in the test dissolver solutions, based on weight of oxide dissolved and volumes of the dissolver solutions, was in good agreement with that analyzed by diode array spectrometry by Laboratories Department. Agreement was excellent between diode array data and the plutonium content calculated from isotopic data from gamma pulse height analysis in $F$ B-Line together with alpha and alpha pulse height analysis. 
DPSPU-88-272-23

J. L. ADAMS

Page 2

February 16, 1988

EXPERIMENTAL

Procedure.

Two dissolutions were made from the single $5 \mathrm{~g}$ sample of HRA-40 provided. The first was $3.012 \mathrm{~g}$ (approx. $2 \mathrm{~mL}$ volume on lightly tamping) of oxide placed in $15.0 \mathrm{~mL}$ of dissolvent, $14 \mathrm{M} \mathrm{HNO}_{3}-0.2 \mathrm{M}$ $\mathrm{HF}$ in a $30-\mathrm{mL} \mathrm{Kimax}^{\circledR}$ graduated centrifuge cone. The second test was with $1.650 \mathrm{~g}$ (about $1.0 \mathrm{~mL}$ tamped) of oxide with $8.5 \mathrm{~mL}$ of dissolvent in a different cone. The tests, conducted in the glove box in the Sep Tech Lab, were run in sequence and not concurrently. Heating was done in a boiling water bath, which generally results in a maximum temperature of $95^{\circ} \mathrm{C}$ in the cone's liquid phase. All mixing was by vigorous, frequent hand shaking of the tightly capped (PVC-1ined) cone and its contents.

Test 非

For the first test, the contents of the capped cone were well mixed, then placed in the boiling water bath. The cone's contents were subsequently mixed every 5 minutes. After 20 minutes, only $0.5 \mathrm{~mL}$ of solids remained. After 40 minutes, no settled solids were noted. Total time in the boiling water bath was 70 minutes. The cone and its contents were allowed to cool for $2 \frac{1}{2}$ hours prior to sampling of the dissolver solution $(16.0 \mathrm{~mL})$ for Pu analysis. No settled solids were noted on sampling. The solution was not centrifuged.

Some 72 hours after dissolution (over a weekend), $600 \mu \mathrm{L}$ of $60 \%$ $\mathrm{Al}\left(\mathrm{NO}_{3}\right)_{3} \cdot 9 \mathrm{H}_{2} \mathrm{O}$ (ANN) was added to a $10-\mathrm{mL}$ aliquot of the dissolver solution. This is the approximate volume ratio now used in the process. On centrifuging, some $200 \mu \mathrm{L}$ of solids were noted in the cone bottom. Thinking they might be due to ANN crystallization, the cone and contents were reheated in a boiling water bath for one hour. The solids persisted. On removing the mother liquor, the solids were found to be insoluble in $1 \mathrm{M} \mathrm{HNO}_{3}$. Upon further washing, the solids appeared to be hydrated silicic acid, $\mathrm{SiO}_{2} \cdot \mathrm{xH}_{2} \mathrm{O}$. They were colorless, indicating that plutonium was probably absent.

Test 非

Since the solids in Test 1 l appeared on centrifugation after some 3 days contact with the Kimax ${ }^{\otimes}$ cone, Test 非 2 was conducted differently, being completed during one 8-hour shift. The $1.650 \mathrm{~g}$ of oxide from HRA-40 was placed into a clean cone and $8.5 \mathrm{~mL}$ of dissolvent added. The cone's contents were mixed vigorously by hand and placed in a boiling water bath. The container's contents were well mixed every 5 minutes during the heating cycle. After 
DPSPU $-88-272-23$

J. L. ADAMS

Page 3

February 16, 1988

one hour, the tube and its contents were centrifuged. Some 250 $\mu L$ solids persisted, but most appeared, because of its texture and color, to be undissolved oxide.

The tube and contents were left in the boiling water bath for an additional hour and then recentrifuged. At this point, some $50 \mu \mathrm{L}$ of siliceous solids appeared in the cone bottom. After cooling to less than $60^{\circ} \mathrm{C}$, a $5-\mathrm{mL}$ aliquot of the $8.5 \mathrm{~mL}$ solution was removed and $0.5 \mathrm{~mL}$ of $60 \%$ ANN added to it. The solution was thoroughly mixed. No solids were noted on centrifugation of the separate dissolver solution aliquot containing ANN. Therefore, addition of the more concentrated ANN to such dissolver solutions did not create a solids problem.

The siliceous solids remaining in the original tube were washed several times with $1 \mathrm{M} \mathrm{HNO}_{3}$. They appeared to be quite similar to those remaining after Test $\# 1$.

Blank Test for Si

Into a clean $30-\mathrm{mL}$ Kimax ${ }^{\circledR}$ centrifuge cone was placed $15 \mathrm{~mL}$ of $14 \mathrm{M} \mathrm{HNO} 3-0.2 \mathrm{M} \mathrm{HF}$ dissolvent. The cone and its contents were heated in a boiling water bath for 1.5 hours and then allowed to stand at the ambient temperature of the laboratory for 72 hours. An aliquot of the dissolvent was removed for silicon analys is by Laboratories Department using DCAP spectrometry. The blank test solution contained $580 \mathrm{ppm} \mathrm{Si}$. Therefore, the $15 \mathrm{~mL}$ of dissolvent contained a total of almost $9 \mathrm{mg}$ silicon, equivalent to $19 \mathrm{mg}$ of silica, $\mathrm{SiO}_{2}$.

The bulk of siliceous solids produced in Test $\# 1$ originated from silica dissolution from the $\mathrm{Kimax}^{\circledR}$ cone. Those resulting in Test \#2 probably resulted mainly from the silica impurity in the oxide.

Analysis of HRA-40 Oxide for Si

A small portion of the original sample furnished the Sep Tech Lab was given to Laboratories Department for emission spectrographic analysis of the silicon content of the oxide as furnished by Hanford. This analysis showed the oxide, as received, to contain $65 \mathrm{ppm}$ $\mathrm{Si}$, or the equivalent of $139 \mathrm{\mu g} \mathrm{SiO}_{2}$ per $\mathrm{g}$ oxide. Hanford analysis of the 6 batches of HRA-40 for silicon were: <10, 15, 12, 14 , 13 , and 18 , for an approximate average of $12 \mathrm{ppm} \mathrm{Si}$, or the equivalent of $26 \mathrm{Hg} \mathrm{\textrm {SiO } _ { 2 }}$ per gram of oxide, a factor of five less than SRP's findings.

Formation of Siliceous Solids in the Disssolver

From a single nominal charge of HRA-40 oxide to the process, based on the SRP silicon results, $56 \mathrm{mg}$ of $\mathrm{SiO}_{2}$ solids could form in 
DPSPU-88-272-23

J. L. ADAMS

Page 4

February 16, 1988

the dissolver. If we assume that the $50 \mu \mathrm{L}$ of solids in Test \#2 2 totally resulted from the $\mathrm{Si}$ impurity $(65 \mathrm{ppm})$ in the 1.65 $g$ of oxide, then a maximum of $12 \mathrm{~mL}$ of siliceous materials could form in the dissolver from each charge of similar scrap oxide.

\section{ACCOUNTABILITY AND MATERIAL BALANCE}

For accountability purposes and mass balance agreement, we wished to compare data from the alpha plus gamma analyses with that from diode array spectrometric analysis of the dissolver solution, discussed later, as well as with the weight of oxide (theoretically considering it to be pure $\mathrm{Pu}^{239-40_{2}}$ ) dissolved in a given volume of solution.

$\underline{\mathrm{Pu} \text { Isotopic Analysis of HRA-40 }}$

L. B. Baker of Laboratories furnished the following isotopic analysis for plutonium in HRA-40, obtained from gamma ray pulse height spectrometry conducted in F B-Line. The sample analyzed was identified as "Seal \#FC1407" by F B-Line.

$\begin{array}{cc}\text { Pu Isotope } & \text { Wt \% } \\ 238 & 0.05250 \\ 239 & 87.5238 \\ 240 & 11.4032 \\ 241 & 0.8394 \\ 242 & 0.1811 \\ \text { (Am } 241 & 5123 \mathrm{ppm})\end{array}$

Alpha Analysis of Test \#1 Dissolver Solution

Replicate alpha analyses produced a total alpha activity of $4.14 \times 1010 \mathrm{~d} / \mathrm{m} / \mathrm{mL}$ in the $16.0 \mathrm{~mL}$ of Test 非 dissolver solution. From alpha pulse height analysis the alpha percent of $\mathrm{Pu}^{239-40}$ was $75.76 \%$. Therefore, the Pu239-40 alpha activity in the Test \#1 dissolver solution was $3.14 \times 10^{10} \mathrm{~d} / \mathrm{m} / \mathrm{mL}$.

$\underline{\text { Pu Content of Test } \#_{1} 1 \text { Dissolver Solution From Alpha \& Gamma Data }}$

To obtain the plutonium content of the Test $⿰ ⿰ 三 丨 ⿰ 丨 三 1$ solution, the wt\% $\mathrm{Pu}^{239}$ and $\mathrm{Pu} 240$ must first be normalized to represent $100 \%$ of the isotopic content of HRA-40 since almost $100 \%$ of the total $\mathrm{Pu}$ alphas come from these two isotopes alone. The following table shows how the normalization was done. 
DPSPU-88-272-23

J. L. ADAMS

Page 5

February 16, 1988

\begin{tabular}{|c|c|c|c|}
\hline Pu I sotope & Wt $\%$ by Gamma & Normalized & Specific Activity $^{2}$ \\
\hline 239 & 87.5238 & 88.4731 & $1.361 \times 10^{11} \mathrm{~d} / \mathrm{m} / \mathrm{g}$ \\
\hline $\begin{array}{c}240 \\
\text { Total }\end{array}$ & $\begin{array}{l}11.4032 \\
98.9270\end{array}$ & $\begin{array}{r}11.5269 \\
100.0000\end{array}$ & $5.057 \times 10^{11} \mathrm{~d} / \mathrm{m} / \mathrm{g}$ \\
\hline
\end{tabular}

Using this data, in 1 gram of $\mathrm{Pu}^{239-40}$ material with the normalized composition, there should be:

\begin{tabular}{ccc} 
Pu Isotope & Alpha d/m/g & Alpha \% \\
\cline { 1 - 2 } 239 & $1.204 \times 10^{11}$ & 67.38 \\
240 & $0.583 \times 10^{11}$ & 32.62 \\
Total & $1.787 \times 10^{11}$ & 100.00.
\end{tabular}

With this data, calculated exclusively from the gamma isotopic analysis, and combining it with the alpha data, we can calculate the total plutonium 239-240 content of the dissolver solution, as :

1) total $\mathrm{d} / \mathrm{m} / \mathrm{ml} \mathrm{Pu} 239-40$ from alpha $=3.14 \times 10^{10}$. (Determined previously.)

Using the alpha percentages calculated from the foregoing data, the dissolver solution from Test 非 should have contained:

2) $\mathrm{Pu}^{239}=3.14 \times 10^{10} \times 0.6738=2.12 \times 10^{10} \mathrm{~d} / \mathrm{m} / \mathrm{mL} \&$ $\mathrm{Pu}^{240}=3.14 \times 10^{10} \times 0.3262=1.02 \times 10^{10} \mathrm{~d} / \mathrm{m} / \mathrm{mL}$.

On converting these activities to weight using the specific activities listed above, then in $1 \mathrm{~mL}$ of Test 1 lissolver solution there should have been:
3) $\mathrm{Pu}_{239}=2.12 \times 10^{10} / 1.36 \times 10^{8} \mathrm{~d} / \mathrm{m} / \mathrm{mg}=156 \mathrm{mg} \mathrm{Pu} 239 / \mathrm{mL}$ $+\mathrm{Pu} 240=1.02 \times 1010 / 5.06 \times 10^{8} \mathrm{~d} / \mathrm{m} / \mathrm{mg}=20 \mathrm{mg} \mathrm{Pu} 240 / \mathrm{mL}$, or $\mathrm{g} / \mathrm{L} \mathrm{Pu} 239-40$ in Test \#1 Diss. Soln. $=176 \mathrm{~g} / \mathrm{L}$

Analysis of Test Dissolver. Solutions by Diode Array Spectrometry

Samples of the dissolver solution from Test \#1 and Test 非 were sent to Laboratories Department for analysis of their total plutonium content using the $\mathrm{Pu}^{+3}$ method with diode array spectrometry. Results were:

Test 非 1 Diss. Soln Test 非 Diss. Soln

Total Pu g/L

175.0

174.5 
J. L. ADAMS

Page 6

February 16,1988

Agreement between the accountability numbers calculated from the alpha plus gamma data with that from diode array analysis is excellent. Test 非 dissolver solution was not subjected to alpha analysis.

Data From Weight Oxide Dissolved in Dissolver Solution Volume

Based on weight of oxide dissolved in Test 非1, $3.012 \mathrm{~g}$ (or 2.656 g. $\mathrm{Pu}$, then if the oxide were $100 \% \mathrm{Pu}^{239} \mathrm{O}_{2}$, the plutonium content of the Test Fl $_{1}$ dissolver solution should have been $166 \mathrm{~g} \mathrm{Pu/L}$.

For Test dissolution \#2, based on weight of oxide dissolyed, 1.650 $g$ (or $1.455 \mathrm{~g} \mathrm{Pu}$ ), and again if the oxide were $100 \% \mathrm{Pu}^{239} \mathrm{O}_{2}$, the plutonium content of the Test $\left.\right|^{2}$ dissolver solution should have been $171 \mathrm{~g} \mathrm{Pu/L}$.

Even fairly good agreement results from comparing these data, the worst accountability case because of assumptions made, with those obtained from the more reliable scientific methods, described above.

\section{CONCLUSIONS}

Plutonium oxide in HRA-40, tested in the Separations Technology Laboratory under conditions similar to those in the process, dissolved without difficulty. Efficient mixing of the oxide with the dissolvent was an absolute necessity to effect complete dissolution.

Residues of silicon solids resulted from silica impurity in the Hanford scrap plutonium oxide plus that dissolved from the $\mathrm{K}^{\mathrm{max}}{ }^{\circledR}$ glass cones used as test containers. SRP emission spectrographic analysis of the oxide showed a silicon impurity level some five times greater than Hanford analytical data. Silica residues from continued dissolutions of such oxides will build up in the dissolver and will be difficult to remove since such solids are relatively intractable to the usual chemicals permitted in SRP processes. Similar residues from a previous Hanford oxide shipment, HRA-37, were characterized in an earlier Sep Tech Lab study 1 and found to be mostly silicon.

Plutonium content of the oxide, as determined by diode array spectrometric analyses of the dissolver solutions from the two test dissolutions, was in excellent agreement with data determined from alpha analysis of the solutions combined with the plutonium isotopic analysis by SRP gamma ray spectrometry. 
J. L. ADAMS

Page 7

February 16, 1988

\section{ACKNOWLEDGMENTS}

I wish to recognize the assistance provided by Laboratories Department in getting necessary information for this report. J. T. Coleman did the emission spectrometric analysis for $S i$ in the oxide. DCAP analyses were overseen by B. K. Mitchell. Laboratories' shift personnel conducted the alpha counting and performed the diode array spectrometry. M. K. Holland was helpful in analyzing this data. L. B. Baker assisted by supplying the plutonium isotopic composition for this batch of Hanford material.

\section{REFERENCES}

1. DPSPU-86-272-60, "Dissolution \& Analysis of Hanford Plutonium Oxide Shipment HRA-37", H. P. Holcomb to D. W. Murdoch, April 25,1986 .

2. "Specific Activities and Decay Constants of Selected Isotopes of Interest in 200 Areas", June 28, 1978.

$\mathrm{HPH} / \mathrm{h}$ 